\title{
CONFLITOS ENTRE O DEVER DO ESTADO À PRESTAÇÃO DE SAÚDE UNIVERSAL E A LIBERDADE RELIGIOSA DE TESTEMUNHA DE JEOVÁ: ESTUDO DE CASO DO RECURSO EXTRAORDINÁRIO No 979742/AM.
}

\author{
CONFLICTS BETWEEN THE STATE'S DUTY TO THE UNIVERSAL HEALTH \\ BENEFIT AND THE RELIGIOUS FREEDOM OF JEOVAH'S WITNESS: STUDY OF \\ CASE TO "RECURSO EXTRAORDINÁRION” 99742/AM."
}

Gustavo Costa Silva ${ }^{111}$

Adriana Galvão Moura Abílio ${ }^{112}$

\begin{abstract}
RESUMO: A Constituição Federal Brasileira estabelece o acesso gratuito à saúde pública como princípio universal através do Sistema Único de Saúde; entretanto, várias são as dificuldades enfrentadas para que esse serviço seja eficaz no país, além das inúmeras demandas travadas junto ao Poder Judiciário para garantir direitos.Também não seria diferente as dificuldades enfrentadas por cidadãos que precisam se socorrer do Poder Público para efetivar o direito à saúde e o direito à liberdade religiosa. Reside nestes direitos (saúde e liberdade religiosa) a tônica do presente artigo, que tem como objetivo analisar um recurso extraordinário 97742/AM de uma pessoa testemunha de Jeová, que pleiteia na justiça uma cirurgia de acordo com os preceitos religiosos por ela adotados, ou seja, sem transfusão de sangue, o que seria um desafio para o Poder Público, além das particularidades que envolvem a matéria. Com a análise de diversos autores, a pesquisa guiou-se pelo método empírico dedutivo, através de livros, artigos científicos, julgados de tribunais e publicações de grandes meios de comunicação, a fim de compreender os elementos subjetivos e objetivos na colisão de princípios que se observa no caso concreto.
\end{abstract}

Palavras-chave: Liberdade Religiosa; Testemunha de Jeová; Direito à Saúde.

\footnotetext{
${ }^{111}$ Advogado, Formado em Direito pelo Centro Universitário da Fundação Educacional de Barretos (UNIFEB). E-mail: gustavocosta.cs@gmail.com.

${ }^{112}$ Advogada - Sócia Galvão Moura Advocacia, possui graduação em Direito pela Universidade de Ribeirão Preto, Doutorado em Direito pela PUC/SP, Bolsista do Programa CAPES/PROSUP, Mestrado em Direito pela Universidade de Ribeirão Preto (UNAERP). Especialização em Direito Econômico e Empresarial pela Fundação Getúlio Vargas - FGV. Atualmente é professora do curso de Direito do Centro Universitário da Fundação Educacional de Barretos (UNIFEB), do IMESB-VC em Bebedouro/SP. Tem experiência na área de Direito, com ênfase em Direito Constitucional, Direitos Humanos e Direito do Trabalho. E-mail: drigm22@hotmail.com.
} 
ABSTRACT: The Constitution of the Federative Republic of Brazil institutes free access to the public health as a universal principle throught National Health System. However, there are many obstacles on its way that does not let this service really effective in the country, as well as the demand of people suing the State, requiring health solutions. Therefore, citizens also face obstacles to see their health and religious rights being accomplished as well. There rights (health and religious liberty) is the purpose of this article what is to analyze an extraordinary case 97742/AM of a Jehovah's Witness, who sued Public Power for a surgery with no blood transfusion, what would coast a high value to the public administration. Several academic titles were used in order to make this article. The research was followed by empiric deductive method, in other words, books, scientific articles, court decisions and relevant publications, with the purpose to understand the subjective and objective elements in the current collision of laws principles.

Keywords: Religious freedom; Jehovah's Witness; Right to health.

\section{INTRODUÇÃO}

Uma das classificações existentes sobre a correspondência da Constituição Federal com a realidade é a nominativa, ou seja, a carta magna busca alcançar o objetivo do bem-estar social, mas ainda carece de uma realização prática eficaz. Esse entendimento se valida, por exemplo, nos diversos problemas judiciais envolvendo conflitos entre a saúde e a liberdade religiosa.

O caso que será analisado no presente artigo destina-se a apresentar os fatos e desdobramentos referentes a um cidadão brasileiro testemunha de Jeová residente no estado do Amazonas que requere em vias judiciais que a União custeie um tratamento não coberto pelo Sistema Único de Saúde, tratamento este que facilmente seria realizado sem prejuízo ao erário público caso fosse possível a realização da transfusão de sangue negada em sua religião.

Para entender o problema em questão, no primeiro item serão transcritos alguns detalhes dos fatos apresentados no decorrer processual do respectivo caso, com a reprodução de alguns trechos das partes envolvidas, a fim de se inteirar detalhadamente do objeto. Com base nisso, será trazido em pesquisa todo o aporte constitucional que cobre a matéria envolvida, bem como será buscado no código de ética médica o comportamento médico em relação a este tipo de conflito. 
Posto isso, em outro capítulo será abordado o comportamento das testemunhas de Jeová para a compreensão da importância de respeitar o direito pessoal e religioso dessas pessoas ao recusar a transfusão de sangue e como a jurisprudência brasileira lida com os processos judiciais em que o objeto problema se encontra na recusa da transfusão de sangue.

O item seguinte será destinado a compreender o papel na forma dos limites e da competência de cada ente federativo na prestação de assistência à saúde tida como universal e igualitária pela constituição e também será buscada na jurisprudência a resposta de como o Estado lida com casos judiciais de prestação de saúde que não estejam enquadrados no Sistema Único de Saúde em geral.

Por fim, serão apresentadas as conclusões do texto, com o objetivo de tentar responder sob a ótica do direito constitucional brasileiro e da realidade prática quem está certo na demanda, que atualmente não se é mais de fato e sim de direito no recurso extraordinário a ser julgado pelo Supremo Tribunal Federal sobre quais os limites da liberdade religiosa na requisição de particularidades no âmbito público.

\section{ESTUdo DE CASO DO PACIENTE TESTEMUNHA DE JEOVÁ E O ESTADO DO AMAZONAS}

Segundo relatos do RE $n^{\circ}$ 979742/AM, objeto de estudo do presente trabalho que neste tópico em partes se transcreve, no ano de 2017 a União, o Estado do Amazonas e o município de Manaus foram condenados pela Turma Recursal do Juizado Especial Federal do Amazonas e Roraima a custear um tratamento de saúde que atualmente não se encontra na rede do Estado para um cidadão por conta de suas convicções religiosas.

Inicialmente, o indivíduo, residente em Manaus, requereu judicialmente uma cirurgia de artroplastia total primária cerâmica a ser realizada na cidade de Itu, no interior do estado de São Paulo, além do custo da viagem, hospedagem, transporte e alimentação, tanto para si como também para um acompanhante durante o período do tratamento.

O processo, ao tramitar perante a $6^{\mathrm{a}}$ Vara Federal da Seção Judiciária do Amazonas, teve julgado procedente o pedido com tutela de urgência sob o 
fundamento dos artigos 196 e 198 da Constituição Federal, sob pena de responsabilidade civil, multa e crime de homicídio culposo.

Os fundamentos foram em tese de que tanto a União quanto os Estados, o Distrito Federal e os Municípios possuem obrigação solidária de promover de forma efetiva a garantia constitucional da prestação de serviço à saúde, independentemente de qualquer divisão de cotas de responsabilidade prevista pela legislação infraconstitucional (vol. 1, p.35).

$\mathrm{Na}$ defesa da União, a mesma afirma ilegitimidade, pois sua competência dentro do SUS é apenas de mera gestora, e cabe diretamente aos municípios e Estados promoverem o efetivo tratamento dos pacientes. Já o Município de Manaus alegou sua incompatibilidade de legitimidade, pois o caso em questão é de nível complexo.

O Estado do Amazonas, por sua vez, também garante em juízo a falta de legitimidade, já que não é de competência estadual propor respectivo custeio, mas também o tratamento a ser custeado foi pedido em São Paulo, logo, um Estado não tem poder de inferir autonomia a outro ente da federação, devendo, portanto, ser papel da União. Nas palavras da defesa do Estado (vol.1, p.77):

O Estado não pode ser constrangido a custear os serviços de transporte e de atendimento médico solicitados pela parte Autora, não apenas porque não se insere em seu raio de competência tal matéria, mas, sobretudo, porque o mesmo não pode ser obrigado a prestar tratamento de saúde fora de seus limites territoriais, com clara violação ao poder de autogoverno do ente central e de Estados-membros.

Outro ponto também debatido na lide foi que com informações advindas do Ministério da Saúde, o autor já havia sido convocado para realizar a cirurgia necessária por uma vaga que se abriu após um cadastro no TFD (tratamento fora de domicílio), programa este que disponibiliza tratamentos de nível complexo fora de domicílio, e o requerente recusou na data agendada ser submetido ao procedimento cirúrgico, e por isso, a mora administrativa.

Diante disto, foi constatado nos laudos processuais que o autor recusou o tratamento agendado em 2014, pois o mesmo seria submetido a cirurgia com transfusão de sangue, o que viola sua índole religiosa. Assim, as requeridas declararam como uma afronta ao princípio da isonomia o autor 
ajuizar determinado pedido, após ter, por arbítrio próprio, recusado realizar o tratamento no seu domicílio por questões peculiares religiosas.

Após recurso extraordinário, o Ministro Roberto Barroso (2018) declarou ser um caso de repercussão geral:

[...] exigir que o sistema de saúde absorva toda e qualquer pretensão individual, como se houvesse na Constituição o direito a um trunfo ilimitado, leva à ruina qualquer tentativa de estruturação de serviços públicos universais e igualitários. Dessa forma, deve-se ponderar não apenas qual bem constitucional deve preponderar no caso concreto, mas também em que medida ou intensidade ele deve preponderar.

Em virtude dessas considerações, existe o debate a ser estudado nos próximos itens deste trabalho sobre esse conflito de direitos fundamentais. No caso em tela, a liberdade de crença religiosa do autor e o dever fundamental do Poder Público de promover, proteger e recuperar a saúde, mediante a elaboração de políticas públicas que garantam o atendimento universal e igualitário à sociedade.

\subsection{Aporte constitucional sobre a matéria}

Após essa importante análise processual, é possível verificar que existe um conflito entre os direitos pretendidos por um único indivíduo e os direitos coletivos de responsabilidade do Estado para satisfazer o bem-estar social sob a ótica dos princípios da isonomia e da razoabilidade.

Antes de tudo, o autor Luiz Antônio Rizzatto Nunes (2002, p.23) destaca que, baseado no contexto histórico internacional social e também do próprio país, o Brasil inaugurou um ordenamento jurídico pautado no princípio histórico da dignidade da pessoa humana como fundamento e valor supremo de um Estado Democrático de Direito.

Quando, no referido caso, a testemunha de Jeová solicita judicialmente a cirurgia de artroplastia sem a transfusão de sangue, ele está invocando seus direitos fundamentais respaldados no art. $5^{\circ}$ da Constituição Federal. 
Tais direitos fundamentais consistem em liberdade religiosa, saúde, e por consequência a vida, já que a saúde é uma qualidade essencial para que o primeiro possa ser mantido; além disso, todos estes direitos são abrigados sob a égide da interpretação do princípio da dignidade da pessoa humana.

Em contrapartida o Estado tem o dever de assegurar a todos o direito à saúde, promovendo assistência de forma gratuita mediante políticas públicas e também econômicas, visando um atendimento universal e igualitário conforme expressa o art. 196 da Constituição Federal.

Sobre o conceito de saúde, a autora Regina Tavares da Silva (2009) define como:

O bem-estar físico e psíquico, relevante para a pessoa individualmente considerada e para a sociedade, já que a doença, se contagiosa for, gera o risco de propagação generalizada, e, mesmo que não o seja, desfalca a interação produtiva, deixando o ser doente de ser contribuinte ativo para tornar-se ônus para todos.

Alexandre de Moraes (2014, p.30) realça que nenhum direito fundamental é ilimitado; os direitos encontram limites dentro do próprio sistema normativo, e assim sendo, não pode ser escusa de nenhum indivíduo para práticas ilícitas ou até mesmo para pedidos extraordinários ao Estado.

Com base nisso, o autor Ingo de Sarlet (2016) expõe que uma das dificuldades referentes ao estudo do direito à saúde é justamente entender o alcance do seu objeto e seus limites objetivos e subjetivos, gerando a discussão em torno da possibilidade do reconhecimento de um direito subjetivo individual ou coletivo a prestações na área da saúde.

Para melhor compreensão, é preciso destacar o entendimento de Dirley Jr. da Cunha (2012, p.28) de que a constituição em sua interação com os fenômenos da vida política e social deve-se moldar e evoluir perante a sociedade que acompanha e, por conseguinte, seu sistema jurídico deve ser compreendido como um conjunto de normas-regras e normas princípios.

As normas regras seguem o conceito de Dworkin (apud Gomes, 2005) do "all or nothing”, objetivando regulamentar determinada situação, se esta ocorre ela incide, caso contrário não, de encontro aos princípios, que são 
segmentos gerais do ordenamento jurídico e, diferentemente das normas, têm caráter abstrato, valendo-se da interpretação jurídica.

A principal diferença entre as duas modalidades de normas acontece quando existe uma colisão entre elas. No entendimento de Robert Alexy (apud Cunha, 2012, p.30) na obra Teoria dos Direitos Fundamentais:

$\mathrm{Na}$ colisão entre princípios - e isso ocorre quando um princípio veda o que o outro permite - um deles deve ceder. Assim, no tocante aos princípios, cuja sobrevivência pode ser conflituosa, vigora a ideia de peso ou valor ou importância, de modo que o princípio de maior peso ou valor ou importância é o que deve preponderar no caso concreto. Com relação às regras, cuja sobrevivência é antinômica, não é possível o conflito: uma regra vale ou não vale.

Portanto, quando há um conflito entre dois princípios é preciso haver uma ponderação entre ambos e sobressair-se o mais importante, de preferência que nenhum direito seja extinto pelo outro, e sim que prevaleça uma harmonia justa entre eles, adequando proporcionalmente o peso de cada um no caso concreto.

Nesse contexto, Humberto Avilla (2011, p.38) precisa ainda mais o conceito proposto por Alexy, deixando evidente que no campo dos princípios o conceito de Dworkin não é válido, de forma que nenhum direito possa ser esvaziado em detrimento de outro, e sim que seja buscada a harmonia entre ambos.

Nas suas palavras:

A distinção entre princípios e regras - segundo Alexy - não pode ser baseada no modo tudo ou nada de aplicação proposto por Dworkin, mas deve resumir-se, sobretudo, a dois fatores: a diferença quanto à colisão, na medida em que os princípios colidentes apenas têm sua realização normativa limitada reciprocamente, ao contrário das regras, cuja colisão é solucionada com a declaração de invalidade de uma delas ou com a abertura de uma exceção que exclua a antinomia; diferença quanto à obrigação que instituem, já que as regras instituem obrigações absolutas, não superadas por normas contrapostas, enquanto os princípios instituem obrigações prima facie, na medida em que podem ser superadas ou derrogadas em função dos outros princípios colidentes. 
De forma complementar, Moraes (2014,p.30) também esclarece:

[...] quando houver conflito entre dois ou mais direitos ou garantias fundamentais, o intérprete deve utilizar-se do princípio da concordância prática ou da harmonização, de forma a coordenar e combinar os bens jurídicos em conflito, evitando o sacrifício total de uns em relação aos outros realizando uma redução proporcional do âmbito de alcance de cada qual (contradição dos princípios), sempre em busca do verdadeiro significado da norma e da harmonia do texto constitucional com sua finalidade precípua.

Com base nisso, na garantia de assistência à saúde pelo Estado é preciso verificar a reserva do possível que se faz do binômio do princípio da razoabilidade da pretensão e a disponibilidade do Estado.

Portanto, a reserva do possível só será de fato um obstáculo dos direitos sociais se o Estado comprovar que não tem realmente condições de dispor as custas necessárias para promover de forma razoável o tratamento, respeitando o princípio da dignidade; essa condição será abordada em outro tópico no decorrer do trabalho.

\subsubsection{Princípio da isonomia e a liberdade religiosa no ordenamento jurídico}

Durante o andamento do processo, foi alegado pelas rés que oferecer o tratamento pedido com a opção de ser realizado sem transfusão de sangue feriria o princípio da isonomia, pois o Estado estaria privilegiando um indivíduo em detrimento de outros por conta de preferências pessoais.

Primordialmente o Brasil, assim como vários outros estados da modernidade, é um país laico nas letras do artigo 19 da Constituição Federal, que aponta a separação entre igreja e Estado. Na íntegra:

Art. 19. É vedado à União, aos Estados, ao Distrito Federal e aos Munícipios: I - estabelecer cultos religiosos ou igrejas, subvencioná-los, embaraçar-lhes o funcionamento ou manter com eles ou seus representantes relações de dependência ou aliança, ressalvada, na forma da lei, a colaboração de interesse público. [...] 
Conforme aponta Roberto Arriada Lorea (2008, p.17), existe uma faceta multicultural muito presente na arte, na gastronomia, no folclore, nas danças, mas não é tão expressiva na religião, ainda que exista.

Em 2008 o Brasil era o terceiro país mais religioso na américa latina, perdendo apenas para Argentina e Bolívia, com 73,6\% da população sendo católica, 15,4\% evangélica, $3,6 \%$ de religiões diversas e apenas 7,4\% sem religião pré-definida (Oro, 2008, p.89).

Este é o resultado da formação muito forte do país em conjunto com o cristianismo trazido pelos portugueses durante o período colonial através dos jesuítas pela formação da Companhia de Jesus (Hernandes, 2010, p. 222).

Estatísticas do jw.org (2019) indicam que o país atualmente conta com aproximadamente 869.537 evangelizadores, ou seja, para cada 240 brasileiros, um é testemunha de Jeová. Comparativamente, o censo demográfico do Instituto Brasileiro de Geografia e Estatística (IBGE) referente ao ano de 2010 apontou 1.393.208 pessoas que se afirmaram testemunhas de Jeová no país.

Sabe-se que a constituição federal traz a liberdade religiosa expressa no art. $5^{\circ}$, VI: "É inviolável a liberdade de consciência e de crença, sendo assegurado o livre exercício dos cultos religiosos e garantida, na forma da lei, a proteção aos locais de culto e a suas liturgias". Outros incisos do mesmo artigo também destacam a garantia da liberdade de crença.

Entretanto, assim como todos os outros direitos fundamentais tidos como invioláveis, com a liberdade religiosa não seria diferente, havendo restrições interpretativas e também normativas.

Consta no artigo $5^{\circ}$ da Constituição Federal, em seu inciso VIII, que: "ninguém será privado de direitos por motivo de crença religiosa ou de convicção filosófica ou política, salvo se as invocar para eximir-se de obrigação legal a todos imposta e recusar-se a cumprir prestação alternativa, fixada em lei”.

Sobre o significado de escusa, o Ministro do Supremo Tribunal Federal Gilmar Mendes (apud Marques, 2014) define como "a forma máxima de respeito à intimidade e à consciência do indivíduo. O Estado abre mão do princípio de que a maioria democrática impõe as normas para todos, em troca de não sacrificar a integridade íntima do indivíduo".

Compreende-se então que um cidadão não pode usar suas crenças pessoais de esfera privada para negar-se a pagar um imposto, pois ele não pode ignorar que ainda que possua sua religião vive em um ambiente público regido por um ordenamento jurídico e social.

Nesse sentido, recentemente vêm despontando diversos conflitos na esfera pública envolvendo a liberdade religiosa, reconhecidos como repercussão geral pelo STF, vide 
exemplos da data alternativa de realização de concursos públicos para praticantes da guarda sabática (RE 611874), possibilidade de fotos com indumentárias em documentos de identificação (RE 859376) e sobre o ensino religioso de forma confessional nas escolas (ADI 4439), já declarado como constitucional em jurisprudência.

Além disso, outro julgamento importante do Supremo Tribunal Federal foi a respeito da legalidade da prática de abate de animais para cultos e rituais religiosos, em recurso extraordinário (RE 494601) do relator ministro Marco Aurélio, que diferentemente de casos como a vaquejada, rinha de galo e outros com finalidades culturais e desportivas, foi julgada constitucional.

O Tribunal deliberou a decisão, assim definida:

O Tribunal, por maioria, negou provimento ao recurso extraordinário, nos termos do voto do Ministro Edson Fachin, Redator para o acórdão, vencidos, em parte, os Ministros Marco Aurélio (Relator), Alexandre de Moraes e Gilmar Mendes, que também admitiam a constitucionalidade da lei, dando-lhe interpretação conforme. Em seguida, por maioria, fixou-se a seguinte tese: "É constitucional a lei de proteção animal que, a fim de resguardar a liberdade religiosa, permite o sacrifício ritual de animais em cultos de religiões de matriz africana", vencido o Ministro Marco Aurélio. Não participaram da fixação da tese os Ministros Ricardo Lewandowski e Gilmar Mendes. Ausente, justificadamente, o Ministro Celso de Mello. Presidência do Ministro Dias Toffoli. Plenário, 28.03.2019.

Semelhante a esses dilemas, ainda é polêmica na França a lei sancionada em 2011 como forma de segurança nacional e garantia da ordem pública que vedou a prática de cobrir o rosto em locais públicos. Segundo reportagem da revista Deutsche Welle (2016), essa medida afetou principalmente as mulheres muçulmanas do país que costumam, pela cultura religiosa, utilizar véus islâmicos como a burca ou niqab, mas conforme publicação no Jornal Nexo (2017), foi declarada como legítima em 2014 pelo Tribunal Europeu dos Direitos Humanos como uma forma de preservação da laicidade do país.

O ponto de vista entre aqueles que não aprovam a lei é de que esta viola o princípio da livre convivência, gerando uma divisão social por intolerância religiosa, e ainda que as mulheres de religião muçulmanas são a exceção no país, não devendo ser o foco e nem mesmo representação de perigo 
à população (Ciganeiro, 2016). Segundo dados do Ministério francês, apenas 908 mulheres foram multadas em toda a vigência da lei, muitas delas reincidentes.

Nesse viés, o país precisa analisar delicadamente qual o impacto dos efeitos de permitir ou não que as liberdades religiosas possam expressar sua autonomia peculiar abertamente na sociedade, pois cada conflito religioso e social possui nuances específicas.

Além disso, deve-se ter ciência de que aplicar a isonomia na sociedade não é necessariamente padronizar um comportamento restringindo direitos, e sim buscar o ideal social aplicando o conceito aristotélico de igualdade: tratar igualmente os iguais e desigualmente os desiguais, na medida de suas desigualdades.

\subsection{A Responsabilidade Médica à luz da Bioética e do Biodireito}

A medicina atual avançou em níveis inimagináveis em diversos âmbitos da saúde, e um deles é na possibilidade de prolongar a vida do indivíduo por muitos anos de maneira artificial.

Entretanto, nem sempre esses métodos tecnológicos podem ser utilizados de maneira que possa ser considerada digna pela pessoa, afinal, no entendimento dos autores Natália Karolensky e Hamilton Henriques (2014, p.276), esse processo já não busca a cura da moléstia e sim apenas o adiamento da morte, o que acaba gerando, por exemplo, várias discussões a respeito da ortotanásia e da eutanásia na relação paciente e médico.

De forma semelhante, explica Aldir Guedes Soriano (2001) que os médicos encontram dilema com testemunhas de Jeová na recusa da transfusão de sangue, isso porque o paciente, quando perde $30 \%$ de sangue, sofre o processo de choque hipovolêmico, que o faz correr iminente risco de vida, que pode ser facilmente evitado com uma transfusão; entretanto, para os adeptos dessa religião tal procedimento não é uma opção.

Negar o ato da transfusão em face de preferir morrer tem impactos muito além da autonomia da própria pessoa, acarretando em efeitos jurídicos para o hospital e ao próprio médico, que não fez o que estava em seu alcance para salvar o paciente.

O Código de Ética Médica é claro em seus artigos 46 e 56, de que o médico sempre deve informar o paciente sobre o procedimento que irá realizar, bem como dos riscos do mesmo, 
para que obtenha a autorização do próprio paciente ou responsável; da mesma forma, é antiético ultrapassar a autonomia do paciente e executar algum procedimento de qualquer natureza contra sua vontade.

Nesse entendimento, o Conselho Federal de Medicina tratou do tema sobre conflitos éticos de maneira que quando o paciente estiver inconsciente ou de alguma maneira impossibilitado de comunicar-se, devem prevalecer as suas diretrizes antecipadas de vontade, que sempre se sobrepõem ao desejo dos familiares e a qualquer outro parecer não médico.

Já nos casos em que não tiver sido manifestada a vontade do paciente, a Resolução

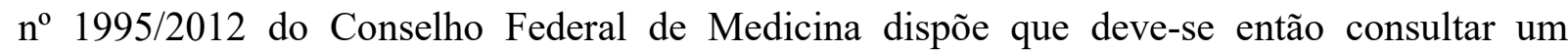
representante que tenha sido designado pelo mesmo e, na falta deste, o médico deve recorrer ao Comitê de Bioética da instituição, caso exista, ou, na falta, à Comissão de Ética Médica do Hospital ou ao Conselho Regional e Federal de Medicina.

Sobre a seguinte Resolução, entende o autor Henrique Moraes Prata (2017, p.188) que ainda existe muita insegurança sobre o tema, principalmente pelo fato de as diretrizes de vontade do paciente serem expressas na forma oral, e que, se anotadas em junta médica e não apenas por médico singular, trariam mais segurança jurídica a respeito dos procedimentos médicos. Nas suas palavras:

Não obstante, apesar da novel Resolução CFM n. 1995/2012, a ausência de legislação sobre a matéria deixa um vácuo de insegurança sobre os limites dessas declarações, o que faz com que alguns tabeliães se neguem a acolhêlas, como pudemos perceber em nossas pesquisas de campo.

Entretanto, o art. $1^{\circ}$ do Código de Ética Médica permite ao médico se abster de todos esses preceitos quando em caso de risco iminente de vida, afinal de contas o princípio fundamental da medicina é o de zelar pela saúde do ser humano, usando o que há de melhor na sua capacidade profissional.

Mas essa capacidade em seu ápice não significa necessariamente realizar cirurgias apenas com a transfusão de sangue, pois atualmente inúmeros são os procedimentos alternativos descobertos e estudados com a possibilidade de execução sem sangue, de acordo com Fabiano da Costa Lima de Sá (2000, p. 323).

Para o médico hematologista Dr. Murilo Carvalho Martins (apud De Sá 2000, p.330), professor e responsável pela disciplina de Hematologia na Universidade Federal do Ceará, de C.R.M 215: 
[...] uma transfusão só deve ser feita quando realmente necessária, pois, se for possível outro procedimento, ele o adotará e orientará seus alunos neste sentido. Contudo existem realmente casos em que só uma transfusão pode salvar a vida e isso deve ser analisado caso a caso.

Portanto, mais uma vez percebe-se que a recusa da transfusão de sangue deve ser analisada caso a caso, uma vez que essa negativa médica pode acarretar diversos problemas ou não, dependendo do caso concreto.

\section{TESTEMUNHA DE JEOVÁ E A RECUSA À TRANSFUSÃO DE SANGUE}

As testemunhas de Jeová, conforme explica o autor Rodrigues Tereza Vieira (2006, p.56), portam um documento chamado "Diretrizes sobre tratamento de saúde e isenção para a equipe médica", no qual consta a necessidade dos praticantes da religião de aceitarem apenas tratamentos alternativos e a recusa total à transfusão de sangue.

Para elas, a Bíblia expressa claramente a necessidade de ter o respeito com o sangue do próprio corpo, conforme uma passagem em Atos dos apóstolos, no Novo Testamento:

Com efeito, parecem bem ao Espírito Santo e a nós não impor outro peso além do seguinte indispensável: que vos abstenhais das carnes sacrificados aos ídolos, do sangue da carne sufocada e da impureza. Dessas coisas fareis bem de vos guardar conscientemente.

Assim, para elas recusar sangue de terceiros é manter a integridade do próprio corpo, além de respeitar o sangue como ele deve ser respeitado, muito além de um instrumento médico, mas divino e intocável.

Este é um entendimento majoritário para essa religião, e não há meios das pessoas mudarem o cerne desse conceito; a prática da transfusão de sangue viola a dignidade e a moral dessas pessoas, que preferem de fato morrer a se submeter a estes tipos de tratamentos médicos. Para elas, é a prova de suas crenças em Deus, e de que seguindo os ensinamentos dispostos na Bíblia conseguirão a redenção no reino do céu (De Sá, 2000).

Exatamente por isso, muitas organizações de apoio a testemunhas de Jeová buscam cada vez mais estabelecer vínculos com hospitais para promover a demanda e incentivar o uso de tratamentos alternativos no país para os praticantes da religião. O resultado dessas comissões é que no mundo todo já existem aproximadamente 40.000 médicos dispostos a executar tratamentos sem a transfusão de sangue (De Sá, 2000). 
Pode-se concluir desse processo de luta religiosa pelos direitos a tratamentos médicos sem transfusão de sangue que as testemunhas de Jeová, embora prefiram morrer a se submeterem a essa modalidade médica, não querem morrer. Não se trata do conflito entre a liberdade religiosa e a vida, e sim da busca pela vida e pelo viver digno.

\subsection{Entendimento Jurisprudencial sobre a recusa à transfusão de sangue pelas testemunhas de Jeová}

Como disposto acima, sobre a situação em que se encontram as testemunhas de Jeová no Brasil, será de extrema importância passar a analisar neste presente tópico algumas decisões dos tribunais em conflitos envolvendo a recusa à transfusão de sangue e a liberdade de crença.

Segue a primeira ementa:

SAÚDE. CIRURGIA. TESTEMUNHA DE JEOVÁ. Distinções, na prestação do serviço público de saúde, para atender às convicções religiosas ferem o direito à igualdade na repartição dos encargos públicos. Daí que a liberdade de religião garantida a todos pela Constituição da República não assegura o direito à pessoa humana de exigir do Estado prestação diferenciada no serviço público para atender às regras e as práticas da fé que professa. Negado seguimento ao recurso (TJ do RS, 2014).

Semelhante ao caso estudado neste trabalho, o caso julgado na ementa acima traz uma testemunha de Jeová que apelou perante a Vigésima Segunda Câmara Cível do Rio Grande do Sul e teve o recurso indeferido.

Observa-se que o fundamento é de que o Estado não deve custear tratamento alternativo por convicções religiosas em face da administração pública, uma vez que a liberdade religiosa consiste na abstenção do Estado.

Pode-se entender então dessa afirmativa que o Estado age sem interferir na escolha religiosa das pessoas, mas também de igual maneira não passa a custear a religião com tratamentos de saúde personalizados ou outras ações positivas que não estejam previstas na Constituição.

Deste julgado em diante, pode se perceber que os tribunais brasileiros adotam a laicidade estatal na forma da ação negativa do Estado em quaisquer casos que possam configurar privilégios religiosos em demandas que envolvem a administração pública. 
A próxima ementa trata de um pedido de uma testemunha de Jeová pelas vias administrativas por um medicamento que funcionaria como uma alternativa a determinado procedimento sem transfusão de sangue.

$\mathrm{O}$ pedido em face de agravo de instrumento foi indeferido, uma vez que o medicamento não comprova a certeza da não necessidade de transfusão, o que acarreta em apenas mais custos para a administração pública em cima de uma incerteza.

Posto isso, faz-se necessário analisar outro caso:

AGRAVO DE INSTRUMENTO. ADMINISTRATIVO. FORNECIMENTO DE MEDICAMENTOS PARA TRATAMENTO ONCOLÓGICO. LIBERDADE DE CRENÇA RELIGIOSA. TESTEMUNHA DE JEOVÁ. MEDICAMENTO DE EFICÁCIA NÃO COMPROVADA. SUBSITITUIÇÃO DE TRANSFUSÃO SANGUÍNEA. IMPOSSIBILIDADE. Em razão da demora em surtir efeito da medicação requerida como alternativa a transfusão de sangue, não se inibe o risco na fase aguda de comprometimento medular, nem se afasta a necessidade de transfusão sanguínea, não sendo recomendável a utilização de medicamento do qual a eficácia não está comprovada adotada somente como terapêutica alternativa, quando há alguma restrição clínica ao uso de hemoderivados. (TRF, 2018).

Em sentido contrário ao das decisões vistas, a $1^{\text {a }}$ Câmara Cível do Tribunal de Justiça do Estado de Minas Gerais deferiu o pedido de recusa à transfusão de sangue em paciente no processo de quimioterapia, caso houvesse o risco da mesma afetar o sistema imunológico, sendo necessária a transfusão, sob a alegação de que sendo a paciente pessoa lúcida e dotada de autodeterminação e capacidade civil, pode decidir sobre os atos individuais da própria vida. Segue a ementa:

EMENTA: PROCESSO CIVIL. CONSTITUCIONAL. AÇÃO CIVIL PÚBLICA. TUTELA ANTECIPADA. CASO DAS TESTEMUNHAS DE JEOVÁ. PACIENTE EM TRATAMENTO QUIMIOTERÁPICO. TRANSFUSÃO DE SANGUE. DIREITO À VIDA. DIGNIDADE DA PESSOA HUMANA. LIBERDADE DE CONSCIÊNCIA E DE CRENÇA. No contexto do confronto entre o postulado da dignidade humana, o direito à vida, à liberdade de consciência e de crença, é possível que aquele que professa a religião denominada Testemunhas de Jeová não seja judicialmente compelido pelo Estado a realizar transfusão de sangue em tratamento quimioterápico, especialmente quando existem outras técnicas alternativas a serem exauridas para a preservação do sistema imunológico. - Hipótese na qual o paciente é pessoa lúcida, capaz e tem condições de autodeterminar-se, estando em alta hospitalar. (TJMG, 2018). 
De acordo com o julgado, não se pode obrigar um indivíduo a submeter-se a qualquer tipo de procedimento que esteja contra a sua natureza, e deferir o pedido de não ser submetido a transfusão de sangue é, além do respeito à liberdade de crença, também o respeito à dignidade da pessoa humana.

Portanto, pode-se concluir que os Tribunais vêm decidindo contra a individualidade das testemunhas de Jeová na recusa à transfusão de sangue em âmbito público, ou seja, quando pleiteiam nas vias judiciais o custeamento pelo Estado de um medicamento ou cirurgia. Interessante notar que dentre as decisões, esta última, em que foi concedido o deferimento do pedido do autor de recusa à transfusão de sangue, era a única que não envolvia obrigação de fazer por parte do Estado.

\section{LIBERDADE RELIGIOSA E A SAÚDE PÚBLICA}

A Constituição atribui ao poder público diversas tarefas de execução do serviço público de saúde, como o estabelecimento do Sistema Único de Saúde (SUS), a concessão da iniciativa privada para promover bens e serviços na área da saúde e o encargo da competência aos legisladores para a regulamentação dessa área. Nas palavras da autora Natale de Souza (2016, p.37):

O título VIII, Seção 2, “da saúde", é composto por 5 artigos. São eles: 196, 197,198,199 e 200. Neles, encontraremos a obrigação do Estado em prover o acesso às ações e serviços de saúde, como o sistema deve ser organizado as diretrizes, a participação complementar da rede privada e algumas das atribuições do sistema único de saúde. Lembre-se que é a partir dessa carta magna que a saúde passa a ser includente, ou seja, universal e igualitária. Sendo mais clara: aqui nasce o SUS.

Nesse sentido, a Carta Magna no seu art. 30, inciso VII, prevê que o atendimento e prestação de saúde à população será de competência dos Municípios, com a cooperação técnica e financeira da União e dos Estados, e conforme o art. 198 da mesma, ainda será de forma integral, descentralizada e hierárquica.

Em complemento a isso, está expresso no Blog do Planalto (Brasília/DF, 2014) que é da responsabilidade da União coordenar os sistemas de saúde de alta complexidade e por meio do Ministério da Saúde planejar e fiscalizar o SUS em todo o país. Compete aos governos estaduais os 
atendimentos complexos da região, criar as políticas de saúde, ajudar na execução das políticas nacionais e realizar o repasse das verbas.

E por fim, é de competência municipal garantir a assistência básica à saúde e prestar os serviços na localidade, e também criar em parceria com os Estados políticas de saúde, utilizar adequadamente as verbas repassadas, bem como organizar os laboratórios, hemocentros e administrar os serviços de saúde, até mesmo os mais complexos.

Entretanto, ainda que cada ente federativo tenha seu âmbito de competência na gestão do SUS, já afirmou o STF (2018) que: "constitui obrigação solidária dos entes da Federação o dever de tornar efetivo o direito à saúde em favor de qualquer pessoa, notadamente de pessoas carentes", logo, não devendo em síntese qualquer dos entes federados se eximir da responsabilidade na prestação de saúde na alegação de ser ilegítima em polo passivo processual, pois a saúde ainda é um dever do Estado conforme o art. 196 da Constituição Federal.

Durante o recurso, também foi alegada pelos entes a incompetência do poder judiciário na intervenção em atos administrativos, pois a proferida sentença condenatória, na obrigação de fazer, feria o princípio da separação dos poderes.

Também compartilha este pensamento a doutrinadora Maria da Silva Zanella Di Pietro (2017, p. 997):

O judiciário não tem funções de planejamento, não tem competência em matéria de destinação de recursos orçamentários, ele não pode determinar à administração que transfira recursos de uma dotação para outra, pois, se o fizer, estará se substituindo ao legislador. O Judiciário é intérprete e aplicador da lei e não pode decidir contra ela, a menos que declare sua inconstitucionalidade.

Referente a essa intervenção, o Ministro Roberto Barroso (2015) expressa o seguinte entendimento:

[...] permite ao Judiciário invalidar atos legislativos ou administrativos quando: (a) não haja adequação entre o fim perseguido e o instrumento empregado; (b) a medida não seja exigível ou necessária, havendo meio alternativo para chegar ao 
mesmo resultado com menor ônus a um direito individual (vedação do excesso); (c) não haja proporcionalidade em sentido estrito, ou seja, o que se perde com a medida é de maior relevo do que aquilo que se ganha.

Dessa forma, é preciso se lembrar do dispositivo do art. $5^{\circ}$, inciso XXXV, que trata sobre a inafastabilidade do poder judiciário. Ainda que os poderes executivo, legislativo e judiciário sejam autônomos e fiscalizadores um do outro, todo direito fundamental gera direito público subjetivo, e se existe lesão ou ameaça a direito, o acesso à justiça deve ser requisitado e não pode ser ausente.

Ou seja, o juiz precisa verificar e sentenciar da maneira mais razoável possível se os atos administrativos pautados nos princípios da própria esfera e da Constituição Federal estão sendo adequados à possibilidade e ao objetivo do caso concreto, com o menor número de perdas possível, e, de outro lado, se o objetivo do autor é razoável às condições do ente público, sendo realmente pedido aquilo que se faz estritamente necessário.

Assim, na garantia de assistência à saúde pelo Estado é preciso verificar a teoria da reserva do possível em cada caso individualmente para se obter uma medida satisfatória. Tal teoria será abordada com mais detalhes no item seguinte.

Seguindo este mesmo alinhamento, a jurisprudência do Supremo Tribunal de Justiça (apud Revista Consultor Jurídico, 2018) demarca que a solicitação de medicamentos não incorporados em atos normativos do SUS exige o cumprimento de alguns requisitos, como a incapacidade financeira do paciente, a comprovação por meio de laudo médico da necessidade do medicamento para o tratamento junto da ineficácia dos disponíveis na rede do SUS, além do registro do medicamente pretendido pela ANVISA.

Depreende-se, então, que é perfeitamente possível conceder medicamentos que não são cobertos pelo SUS quando estes forem essenciais para a manutenção da saúde da pessoa, bem como comprovada a carência da mesma em não ter condições financeiras para arcar com o custo por conta própria. De maneira análoga, portanto, deve-se empreender quando se trata de cirurgias ou aparelhos necessários não cobertos dentro do plano do SUS, conforme a ementa abaixo: 
CONSTITUCIONAL E ADMINISTRATIVO. DIREITO À SAÚDE. MANDADO DE SEGURANÇA. PORTADOR DE MIOCARDIOPATIA CHAGÁSICA CRÔNICA. NECESSIDADE DE IMPLANTAÇÃO DE CARDIOVERSOR-DESFRIBILADOR AUTOMÁTICO PARA GARANTIR A SOBREVIDA DO IMPETRANTE. PROCEDIMENTO NÃO COBERTO PELO SUS. LEGITIMIDADE PASSIVA DA UNIÃO. PERDA DO OBJETO. NÃO-OCORRÊNCIA. SITUAÇÃO FÁTICA CONSOLIDADA. (TRF $1^{\text {a }}$ Região, 2018).

Logo, o Ministério da Saúde e a União Federal devem providenciar os meios necessários para garantir a prestação adequada de saúde para aquele que corre risco de vida ou é portador de doença grave e irreversível.

\subsection{Recurso Extraordinário $n^{\circ}$ 97742/AM ante a aplicação da reserva do possível e do mínimo existencial}

Como já elencado, os conflitos entre os princípios vigentes neste recurso são em destaque os princípios da dignidade da pessoa humana em face do princípio da razoabilidade, ou seja, é necessário que a medida adotada pelo Estado para resolver tal situação seja aquela menos gravosa para os dois polos do processo, que respeite o mínimo existencial da pretensão do autor, mas que também respeite a reserva do possível.

A reserva do possível, explica o autor Franklin Gonçalves Batista (2016), é uma teoria originada no direito alemão a respeito da razoabilidade do objeto que uma pessoa deve buscar na tutela do Estado. No Brasil existem diversas discussões sobre uma possível definição, mas a teoria vem sendo comumente utilizada como justificativa sobre a escassez de recursos públicos na falta de garantias de direitos constitucionais.

A ADPF 45 (Arguição de Descumprimento de Preceito Fundamental) do Min. Celso de Mello (2004) expressa que a reserva do possível é um limite imposto para que o Estado não arque descontroladamente e inconsequentemente com despesas exorbitantes que vão além da possibilidade efetiva dos recursos públicos.

Nesse sentido, de acordo com o autor Daniel W. L. Wang (2008, p.539), para cumprimento de um direito de segunda geração, é preciso que esteja 
em alinhamento com o binômio razoabilidade do pedido e disponibilidade financeira da administração pública para uma efetiva tutela do Estado.

Para Marcelo Alexandrino (2013, p. 253), dessa forma o julgado assegura ao mesmo agir conforme o possível financeiramente, seja concedendo total ou parcialmente a tutela pretendida com base no que for devidamente demonstrado, embora jamais a reserva do possível possa atuar como um "salvo conduto" para que o Estado se escuse de suas obrigações.

Conclui-se a partir dessa ADPF que o direito à saúde, bem como os demais direitos sociais de segunda geração, não são absolutos, assim como qualquer outro direito fundamental; logo, se o Estado não pode deixar de cumprir o mínimo pretendido anulando direitos constitucionais, também não pode ser desdobrar em objetivos impossíveis e prejudiciais ao erário.

Para Di Pietro (2017, p.997), a reserva do possível nem sempre é aceita, pois quando se trata de direitos fundamentais, o Poder Judiciário sempre ordenará a alocação de verba orçamentária para tal fim; essa realidade se tornando uma regra traz sérios prejuízos ao erário. In verbis:

O custo global das prestações positivas assim obtidas é de tal ordem que acaba por praticamente obrigar ao administrador público a destinar, para esse fim, verbas que estariam previstas no orçamento para atender outros objetivos.

Entende-se que permitir ao Estado agir em pretensões individuais como esta atrapalha todo o planejamento coletivo da administração, como, por exemplo, em se tratando de saúde, bancar um tratamento muito caro para apenas um indivíduo traz o prejuízo do gasto de dinheiro que a priori estaria destinado à construção de um hospital público para o tratamento de inúmeras pessoas.

Descendo-se aos lindes do caso concreto, o RE/979742-AM (vol.1, p.5) ilustra que o autor socorre-se do judiciário para que o Estado custeie uma cirurgia de artroplastia primária total cerâmica a ser realizada na cidade de Itu, no interior do estado de São Paulo, como também as passagens aéreas e a hospedagem enquanto durar o período do tratamento, além de oferecer ajuda de custo para suprimentos e despesas com alimentação e transporte, tudo isso para o autor e um acompanhante. 
Mecanismos existem, pois por parte do Estado é possível custear o transporte aéreo e as diárias de alimentação e hospedagem para o paciente e acompanhante, desde que a União, no caso, confirme o agendamento da cirurgia no hospital indicado para autorização do procedimento (vol.1, p.97).

Essa possibilidade ocorre por meio do sistema do TFD (tratamento fora de domicílio) disposto na Portaria $n^{\circ} 55$, de 24 de fevereiro de 1999, do Ministério da Saúde, para casos complexos de alto risco, quando esgotados todos os meios de tratamento no próprio município, observando um teto financeiro para cada município e estado para execução das atribuições.

O grande questionamento é até que ponto pode ser realizado tal tratamento conforme pleiteado judicialmente com base no teto financeiro disponível no erário, já que a estimativa do orçamento definitivo que incide nesse tratamento não é possível de se calcular com os dados disponíveis no processo.

Fato é que a administração pública na gestão do SUS já tratou de todos os requisitos presentes no caso deste recurso em estudo, seja em lidar com procedimentos não cobertos pelo programa, seja em regular os tratamentos que só possuem execução em outro local que não no município do requerente, e a saber que a mesma possui polo passivo, conforme já entendido em diversos casos envolvendo a saúde pelos tribunais do país.

\section{CONCLUSÃO}

Pode ser entendido de maneira geral que uma testemunha de Jeová, no momento em que recusa a transfusão de sangue, coloca em xeque seu direito à vida e à saúde com o seu direito de liberdade de crença; entretanto, isto não acontece no caso estudado, pois ao apresentar e exigir do estado um tratamento opcional, o requerente está buscando na verdade justamente a conciliação destes elementos.

Dessa forma, o principal problema encontrado no âmbito deste recurso extraordinário se encontra no conflito entre o direito à vida, à saúde e à liberdade religiosa, ou, simplificando, o princípio da dignidade da pessoa humana em face aos princípios da razoabilidade e da isonomia. 
Assim, presente uma colisão de princípios, o ideal, por parte dos doutrinadores estudados, é que diferente da norma regra, os princípios, por seu caráter abstrato, devem ser equilibrados quando em conflito, de forma que nenhum necessariamente vede o outro, mas sim que haja uma relação harmônica entre eles, ainda que prevaleça o mais prioritário.

Nesse entendimento, é possível pensar que o Estado não poderia se omitir de prestar a assistência devida ao requerente por descumprimento desse preceito, pois o resultado que ele deve buscar no final da equação é o menos gravoso, imediatamente se pensaria em preservar uma vida humana.

Entretanto, pelo posicionamento dos tribunais em casos semelhantes, é levada em consideração a primazia do interesse público sobre o interesse privado, e não há como deixar de enxergar que o Estado possui alcance limitado financeiramente para cumprir de maneira eficaz todas as responsabilidades de direitos sociais a que é obrigado, ainda mais no âmbito individual.

Portanto, entende-se o porquê de a jurisprudência ser negativa em relação ao tema, mas a pesquisa levantada demonstra que se a priori não é possível a conciliação destes elementos, o mínimo é buscar alternativas, seja cumprindo apenas parcialmente os pedidos, dando prioridade aos mais importantes, seja buscando medidas de barateamento dos mesmos.

Revela-se então a insistente necessidade de reflexão e estudo em cima do assunto, já que a liberdade religiosa está em crescente conflito com os mais variados âmbitos de políticas públicas, e não se pode deixar de lado o princípio de valor supremo buscado pela Constituição Federal, que é a dignidade da pessoa humana.

\section{REFERÊNCIAS}

A BÍBLIA. Atos dos apóstolos. Novo Testamento. $2^{\mathrm{a}}$ ed. rev. atual. Barueri, SP. 1999. p. 896. ALEXANDRINO, Marcelo; PAULO, Vicente. Direito Constitucional Descomplicado. 10 ed. São Paulo: Método, 2013. p.253.

ANDRÉ, M. Lopes, C. Vade Mecum de Jurisprudência Dizer o Direito. $5^{\text {a }}$ edição. Salvador/BA: Ed. Juspodium, 2018.

ÁVILA, Humberto. Teoria dos Princípios da definição à aplicação dos princípios jurídicos. 12. Ed. São Paulo: Malheiros Editores, 2011.

BATISTA, Franklin Gonçalves. A teoria da reserva do possível frente aos direitos fundamentais. Rev. Âmbito Jurídico. Rio Grande, XIX, n. 149. jun de 2016. Disponível em: $<$ http://www.ambito-juridico.com.br/site/?n_link=revista_artigos_leitura\&artigo_id=17359>. Acesso em: 27 dez. 2018. 
BARROSO, Luiz. Roberto. Curso de Direito Constitucional Contemporâneo. 5. ed. São Paulo: Saraiva, 2015. Disponível em: <https://app.saraivadigital.com.Br/leitor/ebook:581213.>. Acesso em: 30 mar. 2018.

BRASIL. ADPF 45 MC/DF. Relator Min. Celso de Mello. Data da publicação: 04.05.2004. Disponível em: <http://www.stf.jus.br/arquivo/informativo/documento/informativo345.htm>. Acesso em: 27. dez. 2018.

. Código de Ética Médica. Conselho Federal de Medicina. Disponível em: http://www.portalmedico.org.br/novocodigo/integra.asp. Acesso em: 04 de nov. 2018.

. Constituição (1988) Constituição da República Federativa do Brasil. 15. ed. atual. e ampl. - São Paulo: Saraiva Educação, 2018.

. Portaria $n^{0}$ 55, de 24 de fevereiro de 1999. Ministério da Saúde. Disponível em: http://bvsms.saude.gov.br/bvs/saudelegis/sas/1999/ptr0055_24_02_1999.html >. Acesso em: 23 set. 2018.

. Resolução n. 1995/2012 do Conselho Federal de Medicina. Disponível em: http://cremesp.org.br. Acesso em: 23 set. 2018.

. Supremo Tribunal Federal. Recurso Extraordinário RE: 979742/AM. Relator: Min. Roberto Barroso. Brasília, DF 2018. DJ: 01/08/2017. Disponível em: $<$ https://www.stf.jus.br/portal/processo/verProcessoAndamento.asp?incidente=5006128>.

Acesso em: 14 fev. 2018.

. Supremo Tribunal Federal. Recurso Extraordinário RE: 494601/RS. Relator: Min. Marco Aurélio. Brasília, DF 2019. DJ: 16/04/2019. Disponível em: $<$ https://portal.stf.jus.br/processos/detalhe.asp?incidente=2419108>. Acesso em: 11 set. 2019.

. Tribunal de Justiça de Minas Gerais. Agravo de Instrumento 1.0701.07.1915196/001. Relator: Des. Alberto Vilas Boas. DJ: 14/08/2007. Belo Horizonte. Disponível em: $<$ https://revistadir.ufv.br/index.php/RevistaDireito-UFV/articledownload/440/63>. Acesso em: 03 nov. 2018.

. Tribunal de Justiça do Rio de Janeiro. Apelação: APL 00002322920138190009 Rio de Janeiro, Bom Jardim, Vara Única. Relator: Juarez Fernandes Folhes. DJ: 30/01/2018. Disponível em: $\quad<$ https://tj-rj.jusbrasil.com.br/jurisprudencia/116649161/apelacao-apl502643620128190021-rj-0050264-3620128190021/inteiro-teor-144013901?ref=serp $>$. Acesso em: 03 nov. 2018.

. Tribunal de Justiça do Rio Grande do Sul. Apelação Cìvel No 70061159398, Vigésima Segunda Câmara Cível. Relator: Maria Isabel de Azevedo Souza, DJ: 29/08/2014. Disponível em: <https://tj-rs.jusbrasil.com.br/jurisprudencia/137157526/apelação-civel-ac70061159398-rs>. Acesso em: 03 nov. 2018.

Tribunal Regional Federal da $4^{\text {a }}$ Região. Agravo de Instumento: AG 47458 RS 2005.04.01.047456-2. Relator: Luiz Carlos de Castro Lugon. Porto Alegre. DJ: 25/04/2006. Disponível em: <https://trf-4.jusbrasil.com.br/jurisprudencia/1218053/agravo-de-instrumentoag-47458?ref=serp. Acesso em: 03 nov. 2018 
CIGANEIRO, Jake. Proibição da burca segue sendo polêmica na França. Portal Deutsche Welle. Berlim, 11. abr. 2016. Disponível em: https://p.dw.com/p/1ITI9. Acesso em: 17 set. 2018.

DI PIETRO, Maria Sylvia Zanella. Direito administrativo. 30a ed. Rev., atual. e ampl. Rio de Janeiro: Ed. Forense, 2017. p.997.

Entes federados têm responsabilidade solidária na assistência à saúde, reafirma STF. Supremo Tribunal Federal. Brasília - DF, 13. mar. 2015. Disponível em: $<$ https://www.stf.jus.br/portal/cms/verNoticiaDetalhe.asp?idConteudo=287303 $>$. Acesso em: 21 set. 2018.

GOMES, Luiz Flávio. Normas, regras e princípios: conceitos e distinções. Revista Jus Navigandi. ISSN 1518-4862, Teresina, ano 10, n. 851, 1 nov. 2005. Disponível em: <https://jus.com.br/artigos/7527>. Acesso em: 3 set. 2018.

HERNANDES, Paulo Romualdo. A Companhia de Jesus no Século XVI e o Brasil. Revista HISTEDBR On-line. Campinas, n. 40, p. 222-244. 2010. Disponível em: $<$ http://www.hisetdbr.fe.unicamp.br/revista/edicoes/40/art14_40.pdf. Acesso em: 9 out. 2018. IBGE - Instituto Brasileiro de Geografia e Estatística. Pesquisa Nacional por amostra de domicílios: $\quad$ religião $2010 . \quad$ Disponível em: $<$ https://cidades.ibge.gov.br/brasil/pesquisa/23/22107>. Acesso em: 03 set. 2019.

KAROLENSKY, N. R. HENRIQUE, H. B. A Recusa de Tratamentos Vitais No Ordenamento Brasileiro: A Escolha é Sua. Coleção Conpedi/Unicuritiba - Vol 3. - Biodireito. Curitiba. p. 276. 2014.

LEHFELD, L. S.; LÉPORE, P. E.; FERREIRA, O. A. V. A.; Monografia Jurídica: guia prático para elaboração do trabalho científico e orientação metodológica. 2 ed. rev., atual. e ampl. Rio de Janeiro: Forense; São Paulo: Editora Método, 2015. 126p.

LOREA, Roberto Arriada et. al. Em Defesa das Liberdades Laicas. 1. ed. Porto Alegre: Livraria do Advogado, 2008.

MARQUES, Gabriel. O Que é Escusa de Consciência? Jus Brasil. [S. I.]. 2014. Disponível em: $<$ https://gabrielmarques.jusbrasil.com.br/artigos/112321019/o-que-e-escusa-de-consciencia $>$. Acesso em: 16 abr. 2018.

MORAES, Alexandre de. Direito constitucional. 30ª edição. São Paulo: Atlas, 2014. 978p.

NUNES, Luiz Antônio Rizzatto. O princípio constitucional da dignidade da pessoa humana. São Paulo: Saraiva, 2002.

ORO, Ari Pedro. A Laicidade na América Latina: uma apreciação antropológica. Porto Alegre: Livraria do Advogado, 2008.

PIMENTEL, Matheus. Por que parte da Europa proíbe o véu islâmico. E o que dizem as muçulmanas. Jornal Nexo. São Paulo 20. Jul. 2017. Disponível em: $<$ https://www.nexojornal.com.br/expresso/2017/07/20/Por-que-parte-da-Europa-proíbe-o-véuislâmico.-E-o-que-dizem-as-muçulmanas>. Acesso em: 17 set. 2018. 
PRATA, Henrique Moraes. Cuidados paliativos e direitos do paciente terminal. Barueri, SP: Manole, 2017.

SÁ, Fabiana Costa Lima de. A Liberdade Religiosa e a Transfusão de Sangue nas Testemunhas de Jeová. Themis: Revista da ESMEC, Fortaleza, v.3, n.1, p. 323-338, 2000. Disponível em: $<$ http://bdjur.stj.jus.br//dspace/handle/2011/18833>. Acesso em: 10 set. 2018.

SARLET, I. W.; MITIDIERO, D. Curso de Direito Constitucional. 5. ed. São Paulo: Saraiva, 2016. Disponível em: <https://app.saraivadigital.com.br/leitor/ebook:580074.>. Acesso em: 30 mar. 2018.

SILVA, Regina. B. T. Responsabilidade Civil na Área da Saúde - Série GVLAW. 2. ed. São Paulo: Saraiva, 2009. Disponível em: https://app.saraivadigital.com.br/leitor/ebook:583082.>. Acesso em: 30 mar. 2018.

SORIANO, Aldir Guedes. Terapia transfusional: Aspectos jurídicos. Revista Jus Navigandi, ISSN 1518-4862, Teresina, ano 6, n. 52, 1 nov. 2001. Disponível em: <https://jus.com.br/artigos/2405>. Acesso em: 4 nov. 2018.

SOUZA, Natale de Oliveira. Legislação do SUS - Esquematizada e Comentada. $1^{\circ}$ ed. Salvador: Ed. Sanar, 2016.

STF altera regras para fornecimento de remédios não listados no SUS. Portal Consultor Jurídico. São Paulo, 13. set. 2018. Disponível em: <https://www.conjur.com.brr/2018-set13/stj-altera-regras-fornecimento-remedios-não-listados-sus>. Acesso em: 03 nov. 2018.

STF vai decidir se liberdade religiosa justifica custeio de tratamento de saúde pelo Estado. Notícias do Supremo Tribunal Federal. Brasília/DF, 07. ago. 2018. Disponível em: $<$ http://www.stf.jus.br/portal/cms/verNoticiaDetalhe.asp?idConteudo=3516690 $>$. Acesso em: 04 mar. 2018.

Testemunhas de Jeová em todo o mundo - Brasil. Site Oficial das Testemunhas de Jeová. São Paulo. Disponível em: <https://www.jw.org/pt/testemunhas-jeova/worldwide/BR/>. Acesso em: 03 set. 2019.

União, estados e municípios têm papéis diferentes na gestão do SUS. Blog do Planalto. Brasilía/DF, 03. out. 2014. Disponível em: <http://www.brasil.gov.br/governo/2014/10/opapel-de-cada-ente-da-federacao-na-gestao-da-saude-publica>. Acesso em: 03 out. 2018.

VIEIRA. Tereza, Rodrigues. Bioética - temas atuais e seus aspectos jurídicos. $1^{\circ} \mathrm{ed}$. Brasília: Ed. Consulex, 2006.

WANG, Daniel W. L. Escassez de Recursos, custos dos direitos e reserva do possível na jurisprudência do STF. Revista Direito GV. São Paulo. 2008. p.539. Disponível em: $<$ https://www.passeidireto.com/arquivo/35040967/adpf-45>. Acesso em: 27 dez. 2018 